\title{
CONFLICTOS DE PODER EN NOSILATIAJ LA BELLEZA
}

\author{
Conflicts of power in Nosilatiaj la belleza
}

Fabián Augusto Soberón*

\section{Resumen}

Nosilatiaj la belleza es atípica por diversas razones. En primer lugar, Nosilatiaj ha sido rodada en una zona marginal para el cine argentino. En segundo lugar, aunque el problema que plantea no es nuevo, sí lo es la consideración de los sectores que toma para mostrar las relaciones de poder. Si bien ha habido películas que han propuesto las relaciones asimétricas entre patrones y sirvientes (pensemos en Los dueños, de Toscano y Radusky, 2013, por ejemplo), Nosilatiaj expone el conflicto entre un sector de la sociedad criolla (la burguesía blanca) y el grupo wichí a través de un asunto que parece menor o insignificante: la belleza del pelo. Ya Michel Foucault había advertido sobre los diferentes modos de control y de disciplinamiento que operan en una sociedad. Es decir, el filósofo francés plantea que no sólo se expresa el poder a través del Estado y de su eje armado (el ejército y la policía) sino que esa relación se exterioriza y se instala a través de diferentes tecnologías: la escuela, el hospital, la familia, etc. Este ensayo se ocupa de dilucidar estos conflictos de poder en el marco de una película producida y realizada desde el norte de Argentina.

$$
<\text { Cine }><\text { Poder }><\text { Noroeste argentino }>
$$

\begin{abstract}
Nosilatiaj or the beauty is atypical for various reasons. First, Nosilatiaj has been filmed in a marginal area. Second, although the problem it poses is not new, the point of view to show power relations is challenging. While there have been films that propose the asymmetrical relationships between bosses and servants (think of Los Dueños, by Toscano and Radusky, for example), Nosilatiaj exposes the conflict between a sector of the criolla society (the white bourgeoisie) and a wichí group through a matter that seems smaller or insignificant: the beauty of the hair. Michel Foucault had already warned about the different modes of control and disciplining that operate in a society. The French philosopher states that the power is not only expressed through by the State and its armed axis (the army and the police), but that power it is externalized and installed through different technologies: schools, hospitals, families, etc. This essay deals with elucidating these conflicts of power within the framework of a film produced and performed from the north of Argentina.
\end{abstract}

$<$ Cinema $><$ Power $><$ Northwest of Argentina $>$

Recibido: 1/10/2017// Aceptado: 10/12/2017

* Lic. en Artes Plásticas. Especialista en Tecnologías Culturales. Jefe de Trabajos Prácticos en asignatura Estética, Escuela de Cine, Video y TV, Universidad Nacional de Tucumán. fsoberon2003@gmail.com 


\section{Introducción}

Nosilatiaj. La belleza, dirigida por Daniela Seggiaro, fue estrenada en 2012 en diversas ciudades del país. El tema y los problemas antropológicos que plantea nos llevan a pensar la zona en la que ha sido filmada la película. Nosilatiaj ha sido rodada en Salta y, en este sentido, es necesario considerar los problemas culturales propios de la zona a la hora de pensar la película.

No es un asunto menor pensar la tradición cinematográfica desde un rincón marginal. Y, sobre todo, en una zona cultural en la que casi no existe una tradición de producción audiovisual o bien es muy reciente la producción. En el caso de la zona norte del país, esto se relaciona con la forma de encarar la narración y, también, con los personajes y lugares que toman los directores para su cine. En este sentido, discutir el rol de la provincia o de las provincias implica considerar ventajas y desventajas. Desde el punto de vista de las desigualdades, está claro que la producción de películas en Tucumán o en Salta - por mencionar sólo dos provincias del norte grande-implica una clara dificultad desde la producción. A la vez, se podría pensar en una doble ventaja: el grupo de cineastas que producen en la provincia lo hacen desde el margen del margen. Si Argentina es el margen de Occidente, una provincia -Córdoba, Mendoza, Tucumán, Santa Fe- es el margen del margen. Basta mencionar el ensayo célebre de Borges (2000) -“El escritor argentino y la tradición"- para evocar la sospecha de privilegio que implica -hoy- volver a pensar la relación entre margen y centro en términos de producción cinematográfica y audiovisual.

Víctor Arancibia, en Nación y puja distributiva en el campo audiovisual, analiza de qué forma, justamente, se reconfiguró el mapa de producciones audiovisuales en el período 2003-2013. El autor nos dice que "A lo largo de estos años, la producción acompañó estos procesos, dando cuenta de las nuevas representaciones de los territorios y de las identidades a la vez que fue poniendo en escena la disputa simbólica de contenidos ahora localizados en las culturas provincianas..." $(2015,10)$. Por eso mismo, se hace necesario profundizar el estudio de los modos y de las retóricas de las producciones realizadas en las provincias considerando las asimetrías existentes entre centro y márgenes y las recientes modalidades de configuración del último cine de la zona.

Cabe destacar, además, que las historias del cine argentino publicadas hasta la fecha, apenas hacen mención al estudio de películas producidas en las provincias por fuera de Buenos Aires. Solo referimos tres títulos para convalidar la afirmación que hicimos anteriormente. Si se revisan las páginas de Breve historia del cine argentino, de César Maranghello, Cien años de cine argentino, de Fernando M. Peña, y Una historia del cine social y político en Argentina (Ana Laura Lusnich y Pablo Piedras, Editores) podremos comprobar que la cuestión de las relaciones entre centro y periferia y la producción reciente de cine realizado desde las provincias sólo es rozado como un asunto menor o de poco interés. Este desinterés refuerza la importancia y la necesidad de estudiar y profundizar la comprensión del campo cinematográfico del norte considerando sobre todo no un concepto regionalista de región sino, en todo caso, la noción más abierta de "zona". Es fundamental para nosotros desactivar el prejuicio regionalista. 
Entendemos por éste aquel prejuicio o ideología (acentuado desde el centro cultural del país y también por las provincias) que sostiene que la provincia es portadora de un saber y de una cultura folclórica reducida al color local y a los tics de un conjunto de patrones asociados a lo propio-centrado en sí mismo. La mirada regionalista de región no solo está interesada en destacar lo local como cultura preciosa y única sino que, además, se niega a valorar las culturas exógenas sean estas de la capital o del extranjero. En contrapartida, proponemos el concepto de zona, no porque creamos que no existen las regiones con características diferenciadas sino más bien porque pensamos que estas zonas exceden el criterio geográfico y porque entendemos que esos espacios "otros" (zonas o regiones) tienen límites difusos que van más allá de lo espacial. En este sentido, lo que nos interesa detectar y desactivar es la perspectiva reduccionista de la mirada regionalista. Por eso mismo, para no quedar asociado al prejuicio que vincula el termino región al regionalismo proponemos modestamente (y como un asunto problemático que merece ser discutido largamente) el concepto de zona ${ }^{1}$.

En el capítulo "Discusión sobre el concepto de zona", de su libro La mayor (1995), Juan José Saer cuestiona el concepto de región en boca de uno de los personajes: "no hay regiones... es más bien difícil precisar el límite de una región... Pongamos por ejemplo dos regiones: la pampa gringa y la costa. Son regiones imaginarias. ¿Hay algún límite entre ellas, un límite real, aparte del que los manuales de geografía han inventado para manejarse más cómodamente?" El texto de Saer pone en entredicho no sólo el concepto de región sino que, además, propone un argumento para pensar cómo hacemos para medir las regiones. En el planteo de Saer aparece la cuestión acerca de las complejas relaciones entre geografía y cultura. ¿Qué relaciones hay entre los accidentes geográficos y el cine? Es decir, ¿el cine de Córdoba o Mendoza es diferente porque ha sido realizado en esos espacios o desde esos espacios? ¿Debemos concluir, como quería Montesquieu, que la geografía determina la cultura? Creemos que es necesario desactivar esta ligazón. Y creemos que la geografía no determina el carácter experimental de una novela o película o la estética del cine. Una película -como hecho estético-- depende menos de la geografía que de la producción, la fotografía, la dirección de actores, la puesta en escena, en suma.

Proponer el concepto de zona no implica negar el estudio de las características de una zona determinada. Es decir, sustituir el concepto de región por el de zona no implica considerar que no existen características o particularidades zonales. En este sentido, me parece fundamental llevar adelante un estudio o una investigación de las zonas marginales (respecto del centro) considerando precisamente las características diferenciadoras de cada zona. Lo que queremos sostener y realizar es precisamente un estudio de casos en los que no solo podamos analizar las peculiaridades de la zona (y

1 En oposición al criterio regionalista, Borges escribió ("El escritor argentino y la tradición”) que los escritores argentinos -como los judíos y los irlandeses- estaban en mejores condiciones para asimilar la tradición universal porque conformaban los márgenes de la cultura europea. Partiendo de esas ideas, ¿qué pensaríamos sobre un escritor o un director de una zona que no esté en el centro de Argentina? Si seguimos la lógica del ensayo de Borges, ¿los escritores y los cineastas que viven en los márgenes de la Argentina están en mejores condiciones para asimilar o procesar la tradición cultural de la Argentina y del mundo? 
en este sentido mostrar las diferencias entre las zonas a través de las películas) sino también pensar de qué forma lo particular puede ser visto como índice de lo universal o de aquello que va más allá de lo particular. Esto significa pensar, con Dilthey, que cada zona conlleva características que les son propias pero que no agotan la riqueza o la expresividad de la zona. Antes bien, el análisis de los casos de películas mostraría que la especificidad de la zona es una especie de vehículo para mostrar y analizar rasgos que trascienden las zonas. Siguiendo esta idea, veremos que la película en cuestión (Nosilatiaj La belleza) trabaja un conflicto propio de la zona norte del país. Sin embargo, esto no significa desconocer que este conflicto puede ser visto como un ejemplo de los múltiples conflictos que atraviesan las diversas zonas y la cultura latinoamericana. En todo caso, el análisis de casos particulares nos permite pensar lo general o los rasgos de los conflictos sociales y culturales que van más allá de lo local o zonal.

El análisis formal de Nosilatiaj apunta a destacar las características estéticas de dicho film. Dicho análisis parte de la idea de que el cine toma un conflicto particular pero no se queda enraizado o condicionado por el conflicto local. El cine de cualquier zona puede trabajar con materiales particulares y tiene la posibilidad de expresar problemas generales o universales. Esta es una característica del cine y del arte. No creemos en la obligatoriedad o necesidad de un cine regionalista o localista. No pensarnos que el cine esté determinado a ser localista. Creemos, como ya lo pensaron Borges y de alguna forma Saer, a su modo, que a pesar de nuestra voluntad localista tenemos la posibilidad de lo universal. Nuestra tradición (nuestro pasado) como artistas o cineastas no es local ni argentina sino universal. En este sentido, el cine realizado en Tucumán o Salta no tiene que proponerse ser norteño, porque ya lo es. Nadie tiene que querer ser norteño: ya lo es antes de proponérselo. El desafío consiste en ver de qué forma se puede ir más allá de lo local para expresar lo universal. Según esta perspectiva, nuestro análisis toma el caso particular de una película de la zona norte para mostrar lo particular y también para ver de que cómo el cine puede ir más allá de lo zonal y puede hablar de lo universal a través de lo particular. De modo que no tiene sentido que el cine se empeñe en lo estrictamente local. Su vocación final es universalista.

Considerando estas cuestiones complejas, este trabajo se propone el análisis de una película producida en la zona del norte de Argentina, más concretamente en Salta, provincia en la que ha sido rodada y producida por la directora Daniela Seggiaro.

Nosilatiaj la belleza es atípica por diversas razones. En primer lugar, Nosilatiaj ha sido rodada en una zona marginal para el cine argentino. En segundo lugar, aunque el problema que plantea no es nuevo, sí lo es la consideración de los sectores que toma para mostrar las relaciones de poder. Si bien ha habido películas que han propuesto las relaciones asimétricas entre patrones y sirvientes (pensemos en Los dueños, de Toscano y Radusky, 2013, por ejemplo), Nosilatiaj expone el conflicto entre un sector de la sociedad criolla (la burguesía blanca) y el grupo wichís a través de un asunto que parece menor o insignificante: la belleza del pelo. Ya Michel Foucault había advertido sobre los diferentes modos de control y de disciplinamiento que operan en una sociedad. Es decir, el filósofo francés plantea que no sólo se expresa el poder a través del Estado 
y de su eje armado (el ejército y la policía) sino que esa relación se exterioriza y se instala a través de diferentes tecnologías: la escuela, el hospital, la familia, etc. Las técnicas de control no solo se dirigen al cuerpo sino que también atraviesan el cuerpo. Dice Foucault: "El control de la sociedad sobre los individuos no se lleva a cabo solo mediante la conciencia o la ideología, sino también en el cuerpo y con el cuerpo“. En el caso de la película Nosialatiaj vemos, claramente, cómo el uso y el abuso de poder se establecen en las situaciones mínimas. ¿Cómo podemos detectar la exposición del conflicto cultural? ¿Cuáles son los recursos audiovisuales que utiliza la directora para mostrar el conflicto de poder?

En tercer lugar, la película combina el uso de recursos audiovisuales (encuadre, voz en off, punto de vista, etc.) que enfatizan la apuesta estética.

\section{Justificación}

Este trabajo expone y analiza los recursos audiovisuales que componen la pieza en su conjunto y detecta las escenas claves que muestran la transformación de las relaciones de poder y subordinación. En este sentido, el trabajo investiga no sólo la construcción narrativa desde el punto de vista de los problemas que plantea sino también de qué forma esos problemas toman cuerpo a través de los elementos estéticos. Como sostiene Gramsci $(2004,391)$, “todos los hombres pueden ser un intelectual pero no todos cumplen la función de intelectual”. Si parafraseamos al pensador italiano, podríamos decir que todos los hombres pueden ejercer el poder pero no todos tienen la función de hacerlo. En el caso de Nosilatiaj La belleza, el elemento detalle que funciona como una sinécdoque es el pelo. La cuestión del pelo podría pensarse como una cuestión menor. Sin embargo, la película se las arregla para poner al pelo en el primer plano narrativo y para mostrar cómo se tensionan las relaciones a través de una situación simple.

De este modo, este trabajo muestra que la mirada de la directora se posa en un detalle para abrir el foco sobre un conflicto mayor y duradero: las relaciones entre criollos y aborígenes.

\section{Conflictos de poder}

La película de Daniela Seggiaro narra un problema cultural que aparece en la conformación cultural de la zona norte: la relación entre la cultura burguesa local-criolla y la cultura aborigen de los wichis. Sin embargo, podríamos decir que a partir de la narración de este conflicto específico (y de su tratamiento estético), la película expone un conflicto que atraviesa a la cultura argentina y a la latinoamericana. Es decir, la película nos permite pensar las particularidades de la zona y a la vez nos permite ver que los conflictos van más allá de la zona. En el caso de Nosilatiaj, a partir de este conflicto cultural, la película plantea la relación de poder entre una señora empleadora de la burguesía local (criolla) y una joven wichí, empleada.

La religiosidad popular católica no está en el centro en la película de Seggiaro. Si bien un primer plano muestra que el hogar de Sara es un hogar católico, no es desde 
esa instancia legitimadora que se produce el rechazo de la cultura aborigen. En todo caso, es la dificultad para aceptar al otro y respetar al otro en su "diferencia" lo que desencadena y estructura la narración fílmica.

Como otras películas producidas en el norte argentino (pensemos en la filmografía de Lucrecia Martel y en la ya mencionada Los dueños, de Toscano y Radusky), Nosilatiaj La belleza narra sucesos que ocurren en pueblos y ciudades del norte argentino. Sin embargo, en esta película el conflicto entre los grupos sociales es diferente. Quizás a partir de este cambio de enfoque es que se puedan entender las diferencias formales: Seggiaro introduce el uso de intertítulos y de una voz evocativa que está fuera de la estética de otros directores de la zona. En este sentido, se puede leer la película de Seggiario como una continuación y una variante diferenciada de la estética de Martel. Es decir, la película de Seggiaro reflexiona sobre un tema particular ambientado en una zona determinada del país (el norte) con un tratamiento estético específico. La película propone una mirada sobre las relaciones conflictivas entre dos culturas a través de un asunto menor, el corte de pelo. Y estas relaciones conflictivas aparecen en la película y representan, a su modo, a las relaciones conflictivas entre otras culturas en Latinoamérica.

El trabajo se inicia con un análisis de la belleza del pelo como eje disparador del conflicto de poder entre dos sectores sociales de la sociedad salteña. Posteriormente, se analizan los recursos formales utilizados por la directora para exponer el conflicto y la modalidad narrativa y el uso de un punto de vista que permite desviarse de la perspectiva didáctica propia del cine político clásico. Si bien la película plantea una relación política clara, la película no se vale de los recursos típicos del cine político.

La conclusión reúne y sintetiza las reflexiones en torno a las cuestiones planteadas y deja abierta la cuestión más amplia del horizonte de los estudios sobre el cine de la zona.

\section{La belleza del pelo}

¿Qué es la belleza? La pregunta formulada por los griegos -Platón dixit ( $E l$ banquete)-- en los orígenes de la cultura occidental repercute de otra forma en la comunidad wichí. En la respuesta a esta pregunta en el caso que nos ocupa, se podría pensar en la tensión que observa y piensa Eugenio Trias (2006) entre lo bello y lo siniestro antes que en una concepción clásica o armónica de belleza. Según Trias, "lo siniestro es condición y límite de lo bello". Es decir, detrás de todo objeto bello existe una plataforma constituida por lo siniestro, una condición que redefine lo que entendemos por belleza. De esta manera podría ser interpretada la idea de belleza del pelo que aparece en la película ya que la parte que cifra la belleza del cuerpo conduce, en el contexto de las relaciones de poder, a una situación siniestra que encubre y envuelve el elemento de belleza propio del personaje wichí. Aún más, se podría decir que la idea de belleza resuena con otro timbre si hacemos la pregunta en el marco de la película de Daniela Saggiero. Es decir, la pregunta por la belleza tiene una respuesta otra en el núcleo de las tensiones entre las dos culturas que entretejen la película: la criolla y la aborigen. Una joven llamada Yola trabaja en una casa de familia criolla 
en un pueblo de Salta. El relato entrelaza dos historias. Por un lado los recuerdos de infancia de la chica wichí con el mandato de la abuela: proteger su cabello, su bien más preciado. El cabello es una sinécdoque de los valores de la comunidad wichí. En cierta medida, la película trabaja por recorte, elevación y suma a partir de un detalle, de un aspecto del cuerpo. Esta parte expresa la compleja red de relaciones y de costumbres que contiene una cultura. También se podría pensar en los vicios, las continuidades y las rupturas que se producen (se construyen) en la relación entre la comunidad aborigen y la criolla. La película plantea desde el inicio la relación de poder, de dominación. La chica wichí trabaja como empleada doméstica en una familia criolla. Esa relación de poder se puede ver en el vínculo patrona-empleada y, sobre todo, en la curiosa amistad entre Guillermina - la hija de la patrona-y Yola. Ambas tienen edades similares. Guillermina se abusa de su rol de chica blanca y le pone limón en el cabello de Yola o le pide que la peine, como si fuera una sirvienta.

La profundización de la relación asimétrica se produce con el robo del cabello. En primer lugar, le cortan -sin permiso - el pelo y luego el espectador asiste -por alusión - al robo directo del cabello. Alejandra Cebrelli (2014) entiende que es la pérdida del único bien que posee lo que le hace reconocer y volver sobre su identidad: "Yola es apreciada por la dueña de casa quien... se preocupa por ella, a pesar de la situación de colonialidad del poder (sobre el cuerpo, sobre el cabello) y del saber (la escuela, la cultura nacional) que contamina toda la relación y confunde a la joven wichí hasta que la pérdida del único bien le permite reconocer su propia identidad cultural, su territorio, su comunidad y su lengua como propios". Es decir, Yola estaba atrapada en la red engañosa de la cultura criolla, como si el grupo de poder tuviera las armas suficientes no solo para atrapar en la red sino también para convencer a los subalternos de que esa cómoda situación de poder es la mejor y la más conveniente. Es la pérdida la que la hace consciente, la que la despierta del sueño dogmático.

Esta operación de apropiación y uso de un valor wichí funciona claramente como una sinécdoque de la relación entre culturas diversas, en tanto que la criolla desprecia, usa y roba a la cultura aborigen. Lo fundamental en la estética de Nosilatiaj es el tratamiento sutil de esta situación. No hay golpes bajos emocionales ni una música que arrolle al espectador llevándolo o forzándolo a ponerse en el lugar de la joven wichí. La película de Seggiaro plantea un problema antropológico a partir de un detalle: toma el asunto del pelo y de la belleza para contraponer dos discursos, el discurso del dominador y el discurso del dominado. La estrategia, entonces, no funciona de forma demagógica sino que opera a través del corte, de la parte que habla del todo: la figura de la sinécdoque. Se podría decir que este recurso cifra o aglutina un asunto, a través de un detalle, y un tratamiento estético. Sentido y forma aparecen unidos en el recurso del robo y apropiación del pelo. De modo que Seggiaro muestra el conflicto moral como un problema estético y expone un detalle de la estética antropológica como un problema moral. Así, la directora nos permite reflexionar sobre las relaciones entre belleza y poder a partir de un conflicto entre dos grupos marginales en la cultura argentina. Sin embargo, este conflicto entre sectores marginales, ilumina un conflicto que va más allá de lo zonal. 
En este marco, es importante destacar que el tratamiento de Seggiario del enfrentamiento particular nos permite reflexionar sobre el concepto de belleza y cómo el propio concepto no es una entelequia sino que depende de cuál sea el marco de pensamiento. Los conceptos no son neutros sino que responden al contexto histórico y al entorno cultural en el que son pensados. A la vez, el conflicto del pelo permite indagar sobre cómo el caso específico de conflicto estético y antropológico abre la reflexión hacia los conflictos culturales de la Argentina y de Latinoamérica.

Quizás resulte esclarecedor considerar la operación que realizó el escritor irlandés James Joyce con su zona. La novela Ulises, de Joyce, está ambientada en la ciudad de Dublín, ciudad que era percibida y conceptualizada como una zona marginal o menor desde el centro de la cultura inglesa y anglosajona. Joyce propuso una ciudad menor como centro de su novela y logró con esa colocación pensar las cuestiones antropológicas y formales (que exceden a su zona) desde un caso particular o marginal. Podríamos pensar que esta es una de las posibilidades epistemológicas para pensar las relaciones de lo que ocurre en la zona norte (en este caso) o provincias del norte en relación con la cultura que está más allá de lo zonal. Nosilatiaj La Belleza propone un conflicto en una zona y ese conflicto marginal ayuda a pensar lo que va más allá de la zona. De modo que la película nos enseña sobre la tensión entre lo zonal y lo extrazonal.

\section{Recursos formales}

La fotografía de Nosilatiaj propone encuadres precisos, largos planos que dejan que la naturaleza se expanda en el cuadro: los árboles, el río, el agua turbia, el suelo árido, las hormigas que se abren a la luz. La historia de Yola (uno de los dos plots que organizan la diégesis) propone el uso de planos abiertos (gran plano general) y planos cerrados: tanto en un caso como en el otro dan cuenta de un cuadro que permite que el tiempo transcurra, que la realidad se expanda en su dimensión temporal. Estos planos demorados, que dejan que el tiempo atraviese la narración, generan una buscada morosidad narrativa: esa morosidad hace "hablar" a los objetos y a los individuos que son captados por el tiempo. A la vez, ciertos planos del entorno son desenfocados ex profeso: el uso del desenfoque va acompañado de la voz fuera de cuadro que refuerza el sentido de la evocación. Es decir, la voz de Yola recuerda su infancia a través del sonido con imágenes abstractas que acentúan el sentido onírico. Sonido y sentido se complementan. Como dice Octavio Paz (1990): la poesía surge de la unión de sonido y sentido como una red inextricable. Quizás el recurso de la abstracción unido al sonido de una lengua "otra" (extranjera: la lengua wichí) genera, junto con los intertítulos una forma de evocación que podríamos asociar a la poesía, al modo de enunciación poético. No hay lirismo sólo en las imágenes puras sino también en la posibilidad de unidad que se genera a partir del recurso mencionado. "El plano representa asimismo la conciencia del cine", dice Pascal Bonitzer, "en la medida en que cada nueva figura del cine ha encarnado en la elección de un nuevo tipo de plano" $(2007,29)$. Podríamos decir que esta idea de Bonitzer es cierta en el caso de la película de Seggiario en un doble sentido. Por un lado, la directora propone un tipo de plano que se ajusta a las necesidades estético-políticas de su film. Es decir, el plano encarna la forma de entender el cine que tiene la directora de Nosilatiaj La belleza en relación clara con su manera 
de plantear el conflicto cultural. La contraposición entre dos modos de montar y narrar es una forma nítida de confrontar dos cosmovisiones y dos concepciones antropológicas. No es casual que las imágenes que estructuran la película trabajen la "inclusión del tiempo", considerando la noción de "imagen-tiempo" propuesta por Gilles Deleuze, ya que de esta manera percibimos los múltiples tiempos simultáneos del ámbito criollo y de la cultura originaria. En segundo lugar, los planos que arman la historia de Yolanda son, de alguna forma, la puesta en escena de la conciencia de ese personaje. Esto significa que los planos conforman una conciencia ligada al recuerdo y a la reconstrucción del pasado en el monte.

Asimismo, de acuerdo al uso de las imágenes podemos reconocer figuras retóricas que organizan el relato. Para Arancibia, el texto fílmico está organizado según dos figuras evidentes: la sinécdoque y la metonimia. Gracias a la sinécdoque, "el uso de las imágenes del monte con una voz en wichí con un registro notablemente lirico posibilita mostrar el lugar en que esa comunidad vive". La metonimia es notable "en el fuera de cuadro que registra el ruido constante de las máquinas desmontando, causa nunca explicitada de la pobreza de Yola y la necesidad de que ésta viva y trabaje en una casa criolla, lejos de su terruño" (2015, 81-82).

Otro de los recursos que construye la instancia narrativa es el trabajo con la profundidad de campo. En la película (y en particular en una escena entre Yola y Antonella), los encuadres contienen tres planos en la profundidad de campo. Un ejemplo es la escena en la que el cantor rasga su guitarra en el patio de la casa mientras la mirada escrutadora de Yola espera a su abuela. Luego, aparece en cuadro, en el fondo, la mujer que la visita: es la madre. Tres planos en profundidad para mostrar, quizás, la situación entre Yola, los criollos y la familia de origen. El uso de un recurso visual permite que veamos en profundidad los sectores sociales y las dificultades de comunicación entre dos culturas. Ninguno de los recursos audiovisuales están usados de forma inocente. Se podría pensar que la retórica audiovisual transmite, en cada detalle, en cada plano y en cada sonido, la instancia narrativa construida por Seggiaro para comunicar un punto de vista sobre los conflictos culturales y políticos. De este modo, podemos sostener que la película es política en un sentido foucaultiano.

Con Godard (2006), decimos que ningún procedimiento formal es inocente y que no sólo el travelling sino también el fuera de campo son cuestiones de ética. Es decir, los recursos audiovisuales utilizados por la directora no son fruto del azar ni de la pereza estética sino que responden a la búsqueda de un efecto de sentido, a la producción de una estética que tiene resonancias éticas. Podríamos decir, entonces, que Nosilatiaj presupone que los planos y los contraplanos son formas transposicionales de la ética, es decir, ningún plano es inocente. Si la cámara se ausenta de un detalle o si, al contrario, sigue a un personaje lo hace porque encuentra que ahí está la manera de interpretar y mostrar las relaciones de poder. Tanto lo que está en campo como el fuera de campo hablan (dicen), narran los entredichos, los silencios y la lucha de fuerza entre los criollos y los wichís. El fuera de campo es central para pensar los códigos y los sobrentendidos entre Antonella y Yola y entre la patrona y Yola. 
Al preguntarnos por la construcción del punto de vista, resulta evidente que la cámara flota entre dos sujetos: la patrona y Yola. Pero es el ojo de Yola -y, sobre todo, la voz de Yola - la que nos hace entrar en el desfasaje, en el desequilibro que hay entre la realidad de los criollos y la vida subordinada de los wichís. Es decir, la película cambia de punto de vista en diferentes escenas. Pero el punto de vista fuerte de Yola es el que nos hace tomar conciencia de que, más allá de cualquier artificio visual, la historia de Yola narra la historia de un desajuste, de un conflicto cultural. El conflicto no solo está narrado a través de la puesta en escena de las luchas de poder entre grupos sociales diferentes sino que las elecciones formales muestran una estética que refuerza el conflicto central. Esto significa que la película busca escenificar el problema de la lucha de poder a través de la propuesta estética y a través de la narración en sí misma.

Los planos de árboles, arroyo, selva, río, cielo, arman un ecosistema visual. Pero hay un detalle que dispara la organización del campo visual y de los sobreentendidos. En este sentido, la estética de la película está hecha de imágenes lentas que dejan entrar el sentido a través de la quietud y permanencia de los planos. La directora confía en el espectador, en la perspicacia del espectador y deja que el sentido se filtre a través de la espera en el plano, de la entrada del tiempo en el plano. Es en esta dirección estética que la película sigue, en cierta forma, la estética del cine de Lucrecia Martel. Aunque, como dijimos, el problema que plantea a través de las estrategias utilizadas nos permite pensar a Nosilatiaj La belleza como una variación con visos particulares a partir del pasado revisitado.

\section{La belleza recuperada}

En la última escena, vemos a Yolanda de vuelta en su hábitat. Ella ha abandonado, podemos deducir, la vida en la sociedad criolla. Yolanda ha recuperado su lugar y su pelo. En este sentido, el cabello es una sinécdoque de su origen y de su identidad. La belleza, entendida en un sentido criollo-occidental, le había traído un problema, a raíz de un conflicto de poder que, justamente, había sido puesto en escena a partir del corte de pelo. El corte abrupto, siniestro, era una operación de amputación antropológica. La belleza criolla se amparaba en lo bello como siniestro, siguiendo la tipología conceptual de Trías. Con el pelo, le quitaban el lazo con sus orígenes. El corte era menos un mero ejercicio de peluquería que una acción política.

El plano final muestra el rostro de Yolanda adulta con el pelo largo. La belleza ha cambiado de sentido, ha sido "recuperada" desde la concepción wichí. De alguna manera, la película de Seggiaro nos indica que el orden (en el cine) ha sido restablecido. Y lo hace a través de una metáfora consecuente con su forma micropolítica de entender el cine y los conflictos de poder en la sociedad argentina. La puesta en escena funciona como una transposición audiovisual de los conflictos sociales. Nosilatiaj La belleza es una película atípica por su manera inteligente y sesgada de discutir la puesta cinematográfica y, a la vez, un asunto crucial en términos de política contemporánea.

La pregunta propuesta en los orígenes griegos (¿qué es la belleza?) es respondida de otro modo en el cierre de la película, un modo que proviene de una cosmovisión ("weltanschauung" en el sentido diltheyano) diferente a la visión de mundo de 
Occidente. En este marco, se podría pensar que la película muestra las diferencias entre dos culturas y a la par nos invita a pensar cuáles serían los términos para un diálogo posible entre los criollos y los wichís. También nos invita a reflexionar sobre la relación entre los occidentales y los otros (los no occidentales), aquellos que no comparten la cosmovisión logocéntrica. Es decir, la película de Seggiario nos ayuda a pensar las relaciones entre margen y centro en diferentes sentidos: estético, cultural y político.

\section{Conclusiones}

Respecto al concepto de zona, creemos que es importante citar in extenso un texto del propio Saer fruto de un diálogo con el escritor Ricardo Piglia (2010, publicado en México por la editorial Mangos de hacha): "Creo que la concepción regionalista de la literatura es una concepción pobre de la literatura. Pero no porque la literatura regional no sea buena. Hay escritores regionales que leo con muchísimo placer. Pero los leo para verificar cosas que no sé, que me gustaría saber, para informarme. Para saber cómo hablan en determinada región... No los leo para encontrarme a mí mismo en esa literatura. Creo que la buena literatura es vertical. Un escritor, cuando construye su obra, ocupa el centro del Universo. Todo individuo es el centro del Universo en todo momento, los otros son una cosa borrosa que está más o menos cerca, ligada a uno por todo tipo de relaciones, cognitivas, afectivas, sensoriales, y no veo por qué un escritor va a limitar ese círculo. Si un escritor se define como regional está, de antemano, impidiéndose tratar y observar cosas del vasto mundo que lo rodea. Si se autodefine como regional se ocupará solamente de la región. ¿Por qué limitarse antes de empezar?” Las consideraciones de Saer sobre el escritor que se autodefine como regionalista podrían ser trasladadas, pensamos, a los directores y realizadores de las diversas zonas del país. Las zonas existen pero la cultura de la zona no debería limitar la producción estética; es decir, no es necesario pensar la idea misma de región como una limitación sino, en todo caso, como una plataforma para crear y/o recrear visiones de mundo a través del arte $^{2}$, visiones que vayan más allá de los límites autoimpuestos desde una mirada reduccionista de la sociedad y del cine ${ }^{3}$.

\footnotetext{
2 Según Dilthey, la idea misma de "wetanschauung" implica una relación entre lo particular y lo general, de modo que el individuo (sea este artista, científico, religioso o político) expresa involuntariamente la cosmovisión de su tiempo. Es decir, vemos en este concepto propuesto por el filósofo alemán la relación entre lo particular y lo general. Para Dilthey, el propio concepto introduce una tensión entre el individuo y el mundo. El individuo (o el grupo de individuos que hacen cine) transmite/n en su obra el todo desde el que parte/n. Así, el mundo es expresado a través del medio o arte. Por ejemplo, el cine expresa la zona que es motivo y objeto del cine sin que el individuo deba enfatizar la relación con "su" zona. A su vez, la zona marginal o especial (norte, por ejemplo) expresa o puede expresar la tradición americana u occidental de una forma implícita o indirecta. "La poesía", dice Dilthey, "por consiguiente, no quiere conocer la realidad, como la ciencia, sino mostrar la significación del acontecer, de las personas y cosas, que reside en las relaciones vitales; así se concentra aquí el misterio de la vida en una conexión interna de esas relaciones vitales que está tejida con personas, destinos y contorno vital". Es decir, Dilthey entiende que la poesía (y nosotros podríamos pensar al cine como una forma poética, artística) no busca dar a conocer la verdad del mundo sino que puede mostrar la significación de la vida de ese tiempo. En este sentido, el arte o el cine no se proponen mostrar el mundo sino que muestran la significación de la vida como un hecho que les corresponde como arte o cine. Cfr. Dlthey. Whilhelm, Teoría de las concepciones del mundo, Barcelona, Altaya.

3 Las novelas y cuentos de escritores como Juan José Saer, Daniel Moyano, Hugo Foguet, Antonio Di
} 
¿Cuál es el horizonte de los estudios sobre el cine de la zona norte? Es necesario decir que el cine producido desde el norte argentino ha tenido escaso estudio desde la instancia académica e, incluso, periodística. Salvo el caso particular de Víctor Arancibia (2015), quien ha analizado diversos filmes y ha indagado en la conformación de un campo audiovisual en el norte centrado en la puja distributiva, no existen estudios abarcadores de la escena de la zona norte. No sólo son escasos los artículos sobre los directores y realizadores del norte sino que, además, las películas tienen una reducida difusión a través de los canales oficiales e, incluso, en las universidades. Entendemos que es fundamental generar una red teórica y crítica que piense las películas generadas por directores de la zona. Sin esta red, es imposible que exista un campo cinematográfico. Si bien es cierto que el campo es más amplio que el que se reduce a la zona, es importante considerar que sin la existencia del propio campo no podremos empezar a pensar las relaciones entre el centro y los márgenes en la producción argentina.

En este marco, podríamos decir que la película de Daniela Seggiaro narra un conflicto social de la conformación cultural del norte y que, desde el seno de esta

Benedetto y Juan José Hernández pueden ser consideradas como ejemplos de obras literarias que escapan o van más allá del criterio regionalista. Este criterio es un criterio paternalista, en cierta medida. Es un criterio que primó en la crítica en un pasado cercano. Por eso es necesario pensar por fuera del criterio regionalista. Creo que ya es tiempo de revisar qué entendemos por escribir una ciudad o una cultura por fuera de la gran ciudad capital. Moyano, Saer, Foguet, Di Benedetto, Castillo escriben sobre/sus ciudades o pueblos sin recurrir al pintoresquismo o reduccionismo folclorista. Crean un espacio simbólico con un lenguaje propio, con un lenguaje experimental (como Saer), personal (Di Benedetto), metafórico y simbólico (Moyano), barroco y filosófico (Foguet) o clásico y arcaizante (Juan José Hernández). Es decir, el espacio, la ciudad, la zona está mediatizada, atravesada por el lenguaje. Sea poético, más narrativo, más referencialista o menos referencialista, en todos los casos es el tratamiento del lenguaje el que da vida al espacio. Sin embargo, no debe pensarse que las zonas son utópicas y autónomas. En este sentido, creo que las zonas literarias o cinematográficas tienen relación con el referente. Pero como el lenguaje es lo que da vida al referente, nunca se trata de realismos costumbristas. En todo caso, lo que si se advierte es que las zonas no son la ciudad de Buenos Aires y las poéticas se constituyen por fuera de la capital y con un fuerte sentido de lo local. Pero sin entender lo local como marca de color local o de mirada cerrada y provinciana. Estos autores arman una zona literaria, inventan un espacio simbólico, casi como Faulkner. Es decir, la zona parte del referente pero luego se emancipa y se convierte en un territorio ficcional, cuasi autónomo, en cierta medida personal, con claras marcas de la estética de cada autor. Es decir, los espacios son espacios de autor.

Es necesario profundizar en el concepto de zona. Entendemos la zona en un sentido triple. En primer lugar, la zona es el espacio literario o cinematográfico elegido por el autor o por el director para sus novelas, cuentos y películas. Es una parte de la ciudad o pueblos que forman parte de la literatura o del cine producidos por un autor-director. En segundo término, la zona es un espacio simbólico, icónico, un conjunto de mitos, leyendas, textos-películas que ya existen sobre la ciudad o sobre lo suburbano que son tomados por el autor-director. O sea, un escritor, pintor o cineasta revisa y reescribe la tradición simbólica de la ciudad y de la cultura suburbana. En tercer lugar, la zona existe como referencia espacial, concreta, material, pero siempre bajo los ojos del autor. No puede haber una ciudad o un espacio como una equis, como una cosa en sí, según el sentido que le ha dado Kant a la idea de cosa en sí, es decir, como realidad absoluta separada de un sujeto. La única modalidad de existencia de una ciudad o espacio es como objeto de un sujeto. El triple sentido del concepto de zona nos muestra la complejidad de dicho concepto y nos incentiva a seguir discutiendo conceptos que solemos heredar y que no discutimos con el necesario detenimiento. Este concepto es crucial para analizar el cine que se produce fuera de los centros de realización cinematográfica y audiovisual. 
narración ilumina o muestra un conflicto que atraviesa la Argentina y una parte de Latinoamérica: la relación de poder entre la burguesía criolla y la comunidad aborigen. En el caso de Nosilatiaj, el conflicto narrado es el de la burguesía salteña y la comunidad de los wichis. En el seno del conflicto social, la película plantea la relación asimétrica entre una señora empleadora de la burguesía local y una joven wichí, empleada. El conflicto no está propuesto de manera demagógica ni pedagógica (por ejemplo, a través de un obvio enfrentamiento político-partidario) sino que el núcleo narrativo se desarrolla a partir de un detalle que escenifica el conflicto: el pelo. En este sentido, es importante destacar que la película realiza un aporte estético y político -en el sentido foucaultiano - ya que centra el conflicto ético en una parte del cuerpo, en un elemento material que no puede ser aislado ni extirpado: la estrategia de control no se focaliza en un objeto o a través de una disciplina convencional sino que lo hace en una parte del cuerpo propiamente dicho. Así, podríamos pensar que la película pone en escena una situación específica de la zona y que, a su vez, dialoga con los conflictos repetidos en la historia argentina. Como diría Juan José Saer, por un momento el conflicto entre aborígenes y criollos ocupa el centro del universo y nos lleva a pensar en las relaciones culposas y dañinas entre los occidentales y los bárbaros o entre los blancos y los otros. De este modo, la película muestra en un campo micro un problema macro: la relación de poder ha sido resignificada en el marco de la zona norte, una zona con una tradición de abusos de poder entre los aristócratas y los subordinados desde los orígenes de las sociedades patriarcales. Queda la pregunta sobre cómo dialoga esta tradición política traumática con el resto de la historia cultural argentina.

\section{Referencias bibliográficas}

Arancibia, V.(2015). Nación y puja distributiva en el campo audiovisual. Identidades, memoria y representaciones sociales en la producción cinematográfica y televisiva del NOA (2003-2013). La Plata: Facultad de Periodismo y Comunicación Social. Tesis doctoral. Aumont, J. y Marie, M. (2006). Diccionario teórico y crítico del cine, Buenos Aires: La marca editora. Amado, A. (2014). "No son como nosotros. Lenguas aborígenes, género y memoria en el cine argentino" en Tránsitos de la mirada. Mujeres que hacen cine, editado por Paulina Betendorff y Agustina Perez Rial. Buenos Aires: Libraria.

AAVV. (2006). "Entrevista con Godard" en La Nouvelle Vague. Sus protagonistas, Buenos Aires: Paidos.

Bonitzer, P. (2007). Desencuadres. Cine y pintura, Buenos Aires: Santiago Arcos Editor. Bonitzer, P. (2007). El campo ciego. Ensayos sobre realismo en el cine, Buenos Aires: Santiago Arcos Editor.

Brunetti, R. (2016). 100 años de cine en Tucumán 1916-2016, Tucumán: Ediciones del Parque. Campo, J. (2012). Cine documental argentino. Entre el arte, la cultura y la política, Buenos Aires: Imago Mundi.

Castro, E. (2016). Lecturas foucaulteanas. Una historia conceptual de la biopolitica, Buenos Aires: UNIPE. 
Cebrelli, A. (2014). "Representaciones de jóvenes mujeres wichís en medios y en la industria cultural. Otredad (es) y trayectos (des) encontrados" en Berguesio, Liliana; Burgos, Ramón, González Perez, Carlos (Compiladores), Mapas comunicacionales y territorios de la experiencia. San Salvador de Jujuy: Ed. EDIUNJU.

Dilthey, W. (1994). Teoría de las concepciones del mundo. Barcelona: Ed. Altaya.

Foucault, M. (1994). Un dialogo sobre el poder, Barcelona: Altaya.

Foucault, M. (1996). La vida de los hombres infames, Buenos Aires: Altamira.

Gramsci, A. (2017). Antología. Selección, traducción y notas de Manuel Sacristán, Buenos Aires: Siglo XXI.

Joyce, J. (2015). Ulises. Traducción de Marcelo Zabaloy. Buenos Aires: Ed El cuenco de plata. Joyce, J. (1997). Ulises. Traducción de José María Valverde. Barcelona: Ed. Tusquets. Lusnich, A. L. y Piedras, P. Editores. (2009). Una historia del cine social y político en Argentina. 1896-1969. Buenos Aires: Nueva Librería.

Maranghello, C. (2005). Breve historia del cine argentino, Barcelona: Laertes.

Paz, O. (1990). Pasión crítica. Buenos Aires: Ed. Seix Barral.

Paz, O. (1985). La otra voz. Poesía y fin de siglo. Barcelona: Ed. Sudamericana

Peña, F. M. (2012). Cien años de cine argentino. Buenos Aires: Biblos.

Piglia, R. y Saer, J. J. (2010). Diálogo, México: Mangos de hacha.

Platón. (2000). El banquete. Barcelona; Gredos.

Saer, J. J. (1995). La mayor, Buenos Aires: Seix Barral.

Trías, E. (2006). Lo bello y lo siniestro. Barcelona: Ariel. 